\title{
Correlation between host specificity and genetic diversity for the muscle-dwelling fish parasite Myxobolus pseudodispar: examples of myxozoan host-shift?
}

\author{
Barbara Forró and Edit Eszterbauer
}

Institute for Veterinary Medical Research, Centre for Agricultural Research, Hungarian Academy of Sciences - Fish Parasitology, Budapest, Hungary

\begin{abstract}
Myxobolus pseudodispar Gorbunova, 1936 (Myxozoa) is capable of infecting and developing mature myxospores in several cyprinid species. However, M. pseudodispar isolates from different fish show up to 5\% differences in the SSU rDNA sequences. This is an unusually large intraspecific difference for myxozoans and only some of the muscle-dwelling myxozoan species possess such a high genetic variability. We intended to study the correlation between the host specificity and the phylogenetic relationship of the parasite isolates, and to find experimental proof for the putatively wide host range of $M$. pseudodispar with cross-infection experiments and phylogenetic analyses based on SSU rDNA. The experimental findings distinguished 'primary' and less-susceptible 'secondary' hosts. With some exceptions, M. pseudodispar isolates showed a tendency to cluster according to the fish host on the phylogenetic tree. Experimental and phylogenetic findings suggest the cryptic nature of the species. It is likely that host-shift occurred for M. pseudodispar and the parasite speciation in progress might explain the high genetic diversity among isolates which are morphologically indistinguishable.
\end{abstract}

Keywords: Myxozoa, cross-infection, SSU rDNA, molecular phylogeny, Cyprinidae, host specificity

Myxozoans are a widespread and diverse taxon of Cnidaria, which includes more than 2200 species in 64 genera, and the number of the described species is continuously rising (Lom and Dyková 2006, Fiala et al. 2015). The largest genus within Myxozoa is Myxobolus Bütschli, 1882 with almost 900 valid species (Eiras et al. 2005, 2014, Liu et al. 2014, Naldoni et al. 2015, Székely et al. 2015).

Myxobolus pseudodispar Gorbunova, 1936 is one of the most common freshwater, muscle-dwelling parasite of roach Rutilus rutilus (Linnaeus) in Europe. Besides roach, the parasite has been detected in other cyprinid species such as ruddScardinius erythrophthalmus (Linnaeus), in common bream - Abramis brama (Linnaeus), common bleak - Alburnus alburnus (Linnaeus) and white bream - Blicca bjoerkna (Linnaeus) (Baska 1987). Considering the characteristic morphological features of myxospores of M. pseudodispar developing in fish host (i.e. asymmetrical spore shape and polar capsules different in size), it was regarded as valid species (Baska 1987). However, Lom and Dyková (1992) later considered M. pseudodispar as a junior synonym of Myxobolus cyprini Doflein, 1898 and morphological variability was explained by spore maturation within parasite plasmodia.

The identification of different Myxobolus spp. based on morphology is often difficult due to the simplified spore shape (Molnár 1994). It is already well-known that besides phenotypic features such as morphological characteristics of myxo- and actinospores, host, organ and tissue specificity of the parasites needs to be considered, and molecular genetic characterisation of at least the SSU/LSU rDNA is also necessary for the accurate identification/description of a myxozoan species (Eszterbauer 2004, Fiala et al. 2015, Molnár and Eszterbauer 2015). The phylogenetic analysis of ten isolates of $M$. pseudodispar originating from four host species (roach, rudd, common bream and white bream) showed correlation with the phylogeny of their fish hosts (Molnár et al. 2002). Their findings clearly distinguished $M$. pseudodispar from the closely related species M. cyprini and Myxobolus musculi Keisselitz, 1908, and confirmed the validity of the species.

Earlier studies suggested that strict host specificity occured in Myxobolus spp. with the same frequency as relatively broad host range species (Molnár 1994, Molnár et al. 2002, Fiala 2006). Molnár and Eszterbauer (2015) reported that myxosporeans in fish are principally strictly host-specific parasites. When a species has only one fish host, it is considered as oioxenic species, such as Myxobolus drjagini (Akhmerov, 1954) developing only in silver carp - Hypophthalmichthys molitrix (Valenciennes). In contrast, stenoxenic species are capable of developing in limited number of closely related species, e.g. Myxobolus pavlovskii (Akhmerov, 1954) infects silver carp and also bighead carp (Hypophthalmichthys nobilis Richardson),

Address for correspondence: E. Eszterbauer, Institute for Veterinary Medical Research, Centre for Agricultural Research, Hungarian Academy of Sciences, P.O. Box 18, H-1581 Budapest, Hungary. Phone: +36 1 467-4067; Fax: +36 1 467-4076; Email: eszterbauer.edit@agrar.mta.hu 
Table 1. Isolates of Myxobolus pseudodispar Gorbunova, 1936 (Mp) examined in the present study. Myxospores were collected from naturally infected fishes in Hungary. Mp R-T50 triactinomyxon (TAM) isolate was obtained from in vivo laboratory-maintained life cycle, but the origin of myxospore (i.e. fish host and locality) is also indicated.

\begin{tabular}{|c|c|c|c|c|c|c|}
\hline Identifier & Spore type & Fish host & Locality & Year of collection & Acc. number & $\mathrm{F}-\mathrm{W}^{*}$ \\
\hline Mp SE-13 & myxospore & Scardinius erythrophthalmus (Linnaeus) & Lake Balaton & 1999 & KU340976 & n.d. \\
\hline Mp SE-47 & myxospore & Scardinius erythrophthalmus & Lake Balaton & 2001 & KU340977 & n.d. \\
\hline Mp SE-F68 & myxospore & Scardinius erythrophthalmus & Lake Balaton & 2014 & KU340978 & - \\
\hline Mp SE-F69 & myxospore & Scardinius erythrophthalmus & Lake Balaton & 2014 & KU340979 & - \\
\hline Mp SE-90B & myxospore & Scardinius erythrophthalmus & Lake Balaton & 2007 & KU340980 & - \\
\hline Mp A-102B & myxospore & Alburnus alburnus (Linnaeus) & Lake Balaton & 2006 & KU340981 & n.d. \\
\hline Mp A-103B & myxospore & Alburnus alburnus & Lake Balaton & 2005 & KU340982 & n.d. \\
\hline Mp AB-1 & myxospore & Abramis brama (Linnaeus) & Lake Balaton & 2013 & KU340983 & - \\
\hline Mp AB-49 & myxospore & Abramis brama & Lake Balaton & 2000 & KU340984 & n.d. \\
\hline Mp AB-52 & myxospore & Abramis brama & Lake Balaton & 2001 & KU340985 & n.d. \\
\hline Mp BL-1 & myxospore & Blicca bjoerkna (Linnaeus) & Lake Balaton & 2013 & KU340986 & + \\
\hline Mp BL-56 & myxospore & Blicca bjoerkna & Lake Balaton & 2001 & KU340987 & n.d. \\
\hline Mp R-91B & myxospore & Rutilus rutilus (Linnaeus) & Lake Balaton & 2007 & KU340988 & n.d. \\
\hline Mp R-92B & myxospore & Rutilus rutilus & Lake Balaton & 2007 & KU340989 & + \\
\hline Mp R-93B & myxospore & Rutilus rutilus & Fish pond at Százhalombatta & 2007 & KU340990 & + \\
\hline Mp R-T42 & myxospore & Rutilus rutilus & Lake Balaton & 2013 & KU340991 & + \\
\hline Mp R-T50** & TAM & Rutilus rutilus $* * *$ & Fish pond at Aufsess, Germany & 2013 & EF466088 & + \\
\hline
\end{tabular}

* F-W - transmission of myxospore (from fish) to worm (intraoligochaete development: - failed; + successful; n.d. not performed; ** TAMs from laboratory-maintained life cycle; also referred as Mp Lineage GER; *** origin of lab-maintained life cycle.

and Myxobolus cerebralis (Hofer, 1903) is able to infect at least four salmonid genera (Molnár and Eszterbauer 2015).

Myxobolus pseudodispar is considered stenoxenic according to the range of its susceptible fish hosts species (Molnár et al. 2002). Molnár et al. (2002) suggested that morphologically indistinguishable species of Myxobolus from different cyprinid hosts do not belong to the same species. This hypothesis can be proven by cross-infection experiments on fish species susceptible to the parasite. Eszterbauer (2013) found 5\% differences in SSU rDNA sequences of $M$. pseudodispar from different host fish, but morphology of the spores and tissue tropism were similar. This raises the question whether $M$. pseudodispar should be considered a stenoxenic species or a cryptic species complex which has to be taxonomically revised.

In the present study, we examined the genetic diversity of isolates of $M$. pseudodispar collected from various cyprinid fishes. Besides the examination of host specificity in relation to the phylogenetic clustering of parasite isolates, putative host-shift was studied under experimental condition using different cyprinid host species (i.e. fish exposure trials), including the type host Rutilus rutilus. Furthermore, fish-to-worm transmission experiments (i.e. oligochaetes exposure trials) were performed with the myxospores obtained from natural infections to analyse the infectivity of the examined parasite isolates.

\section{MATERIALS AND METHODS}

\section{Parasites and hosts}

For phylogenetic analyses and oligochaete exposure, isolates of Myxobolus pseudodispar from naturally infected fish species were collected mainly in Lake Balaton, whereas one isolate originated from the Temperate Water Fish Hatchery at Százhalombatta and the Aufsess Fish Hatchery in Germany, respectively (Table 1). Collected muscle samples containing myxospores were obtained from roach (Rutilus rutilus), rudd (Scardinius erythrophthalmus), common bream (Abramis brama), white bream (Blicca bjoerkna) and common bleak (Alburnus alburnus) (Table 1).

Fish were euthanised with the overdose of tricaine-methanesulfonate (MS 222, Sigma-Aldrich, Budapest, Hungary), followed by severance of the spinal cord and the complete dissection of fish. Squash preparations of muscle tissue were examined under light microscope Axiostar Plus (Zeiss, Oberkochen, Germany) for the presence of plasmodia of M. pseudodispar. Plasmodia were collected into $1.5 \mathrm{ml}$ microcentrifuge tubes and stored at $-20^{\circ} \mathrm{C}$ for molecular biological examination. Fish muscle homogenates were used for myxospore counting and for the oligochaete exposure trials. Myxospores were counted in $20 \mu \mathrm{l}$ tissue homogenate on a microscopic slide with $20 \times 20 \mathrm{~mm}$ coverslip under a light microscope in three replicates as per Eszterbauer et al. (2015a).

The so-called German lineage (Lineage GER $=$ Mp R-T50) of triactinomyxon (TAM) of M. pseudodispar was used in both fish exposure trials (Table 1). TAMs were less than two days old. TAMs were harvested by filtering through the water in laboratory maintained oligochaete cultures using $20 \mu \mathrm{m}$ nylon mesh before use (Kallert and El-Matbouli 2008, Eszterbauer et al. 2009). The original isolate was characterised by Kallert et al. (2007) and the life cycle of the lineage is maintained under laboratory conditions in our laboratory for several years. The maintenance of the parasite's life cycle was conducted according to Eszterbauer et al. (2015b). The genetic identity of the myxospores and the TAMs obtained from the life cycle and from the successful trials of oligochaete exposure (Table 1) was confirmed with DNA sequencing regularly.

Oligochaetes used for the exposure trials were obtained from the parasite-free laboratory cultures maintained in the Institute for Veterinary Medical Research, Budapest, Hungary. Parasite-free fish stocks for the infection experiments were also reared in the same laboratory under parasite-free conditions.

\section{Fish exposure trials}

Two infection trials were performed using fish of different age and/or species. In experiment No. 1, roach were one year old, common bream were two years old and rudd were three years old. 
Table 2. Oligonucleotides used for PCR and/or DNA sequencing.

\begin{tabular}{lll}
\hline Name of oligonucleotides & Sequence 5'-3' & Reference \\
\hline EriB1 & ACCTGGTTGATCCTGCCAG & Barta et al. 1997 \\
EriB10 & CTTCCGCAGGTTCACCTACGG & Barta et al. 1997 \\
Myx4R & CTGACAGATCACTCCACGAAC & Hallett and Diamant 2001 \\
MB5 & GGTGATGATTAACAGGAGCGGT & Molnár et al. 2002 \\
SphF & ACTCGTTGGTAAGGTAGTGGCT & Eszterbauer and Székely 2004 \\
SphR & GTTACCATTGTAGCGCGCGT & Eszterbauer and Székely 2004 \\
MpFnested & TCACCCGCCAAAGTACGATTGT & Present study \\
MpRnested & CGAAACCTGCTTTTGCCTCTTA & Present study \\
Tub16SF & AACGGCCGCGGTATCCTG & Beauchamp et al. 2001 \\
Tub16SR & TAARCCAACATYGAGGTGCCA & Beauchamp et al. 2001 \\
\hline
\end{tabular}

In experiment No. 2, the susceptibility of fish species of the same age was compared, and one year old roach and rudd specimens were used (1+ bream was not available).

Fish were exposed individually to 3000 TAMs at $20^{\circ} \mathrm{C}$, in $500 \mathrm{ml}$ dechlorinated tap water for $3 \mathrm{~h}$. TAM controls were kept under the same condition without fish in each experiment to confirm their viability under the exposure conditions. In experiment No. 1, 16 specimens of roach, rudd and common bream were individually exposed with $M$. pseudodispar TAMs of Lineage GER, respectively. In experiment No. 2, 20 roach and rudd specimens were exposed the same way, respectively.

Fish groups were kept in separate aquaria after the individual exposure and were fed daily with Perla fish pellet (Skretting, Stavanger, Norway) and frozen Artemia salina (Linnaeus) (vanGerven, Son \& Brengel, Netherlands). Fish were kept in aerated aquaria without water flow-through at $20^{\circ} \mathrm{C}$. Three months post exposure (p.e.) fish were euthanised with $200 \mathrm{mg} / 1 \mathrm{MS} 222$ and stored at $-20^{\circ} \mathrm{C}$ until further use. For myxospore counting, the entire musculature of every fish specimens was individually homogenised with a kitchen blender. The homogenate was settled at $4{ }^{\circ} \mathrm{C}$ and the supernatant was carefully replaced twice a day for 2 days to wash the pellet (containing the settled myxospores) prior to counting. Thereafter, the pellet of every sample was diluted with tap water to $50 \mathrm{ml}$ in experiment No. 1 and $10 \mathrm{ml}$ in exp No. 2. Myxospores were counted by light microscopy (Zeiss Axiostar Plus) in $20 \mu \mathrm{l}$ fish homogenate in six replicates and three replicates in experiment No. 2. Based on the counted spore number data, the prevalence, the mean intensity and the abundance of infection were calculated and compared among fish species. Statistical analyses were performed using the R program ( $\mathrm{R}$ Core Team 2003) for Windows with Tinn-R Editor 3.0.3.6 (Faria et al. 2013). Kruskal-Wallis test was used to analyse the differences in infection intensity among infected groups.

\section{Oligochaete exposure trials}

Isolates of myxospores of M. pseudodispar from naturally infected roach, rudd, common bream and white bream originating from Lake Balaton, Hungary, were used for the exposure of parasite-free cultures of oligochaetes as per Marton and Eszterbauer (2012) (Table 1). Oligochaetes (weight ca 5-7 g) were exposed with $\mathrm{ca} 1 \times 10^{6} \mathrm{M}$. pseudodispar myxospores from roach and rudd and $1 \times 10^{5}$ from common bream and from white bream, respectively. Exposed worms were kept in 51 plastic box containing a mixture of autoclaved mud and sand, filled with aerated water. Worm cultures were fed with a mixture of frozen minced lettuce, frozen Artemia (TropiCarry, China) or chironomid larvae (van-
Gerven) and Spirulina powder (maBitec, Hamburg, Germany) once in every two weeks. From 2 months p.e. the water in the cultures of oligochaetes was filtered with $20 \mu$ m nylon mesh weekly for the detection of parasite TAMs (Kallert et al. 2005, 2007, Marton and Eszterbauer 2011, 2012, Eszterbauer et al. 2015b).

\section{Molecular methods}

For DNA extraction, samples were homogenised with a micropestle (Eppendorf, Vienna, Austria) in $1.5 \mathrm{ml}$ microcentrifuge tube (Greiner, Mosonmagyaróvár, Hungary), and centrifuged at $7000 \times \mathrm{g}$ for $5 \mathrm{~min}$ in tabletop centrifuge 5424R (Eppendorf) following the protocol described by Eszterbauer et al. (2013). Thereafter $500 \mu \mathrm{l}$ lysis buffer $(100 \mathrm{mM} \mathrm{NaCl}, 10 \mathrm{mM}$ Tris, $10 \mathrm{mM}$ EDTA, $0.2 \%$ SDS, and $0.4 \mathrm{mg} / \mathrm{ml}$ proteinase $\mathrm{K}$ ) was added to the pellet and incubated at $55^{\circ} \mathrm{C}$ for $2-3 \mathrm{~h}$. For DNA purification, Miniprep Express Matrix (Bio101 Inc., MP Biomedicals, Santa Ana, CA, USA) was used as per Eszterbauer (2004).

The SSU rDNA of $M$. pseudodispar was amplified in the total volume of $25 \mu \mathrm{l}$ with a semi-nested PCR assay using the primer pair EriB1 and EriB10 in the first round (Table 2). The firstround PCR contained 10-50 ng extracted DNA, $1 \times$ Taq PCR reaction buffer (Thermo Scientific, Fermentas, Vilnius, Lithuania), $1.5 \mathrm{mM} \mathrm{MgCl} 2,0.2 \mathrm{mM}$ dNTP mix (Sigma-Aldrich), $0.25 \mu \mathrm{M}$ of each primer, and $1.25 \mathrm{u}$ of recombinant Taq DNA polymerase (Thermo Scientific, Fermentas). Amplification conditions were: initial denaturation at $95^{\circ} \mathrm{C}$ for $5 \mathrm{~min}$, then $95^{\circ} \mathrm{C}$ for $50 \mathrm{~s}, 52^{\circ} \mathrm{C}$ for $50 \mathrm{~s}$ and $72^{\circ} \mathrm{C}$ for $2 \mathrm{~min}$ for 35 cycles, with a terminal extension at $72{ }^{\circ} \mathrm{C}$ for $7 \mathrm{~min}$. The result was visualised by agarose gel electrophoresis on 1.0\% agarose gel in Tris-acetat-EDTA (TAE). It was followed by a second-round PCR using the primer pairs EriB1 - MpRnested (approximately 980 bp long PCR product) and MpFnested - EriB10 (740 bp) (alternatively EriB1 - SphR and SphF - EriB10; 1050 bp and 1600 bp), respectively. The primers MpFnested and MpRnested were both M. pseudodispar-specific oligonucleotides designed in the present study (Table 2). The PCR mastermix and amplification conditions were the same as described above, except the annealing temperature that was $59^{\circ} \mathrm{C}$ in the second-round reaction. The PCR products were purified with MEGAquick-spin Total Fragment DNA Purification kit (Intron Biotechnology, Gyeonggi-do, Korea).

Randomly collected individuals from the exposed oligochaete stocks (3 oligochaete stocks; 15 individuals per stock) were identified using the tubificid-specific primer pair Tub16SF and Tub16SR that amplified the 16S rDNA of oligochaetes (Table 2). The reaction volume was $25 \mu \mathrm{l}$, which contained $10-50 \mathrm{ng}$ extracted DNA, $1 \times$ Taq PCR reaction buffer (Thermo Scientific, 
Table 3. The infection prevalence and mean intensity in experiment No. 1. Three fish species were exposed with Lineage GER TAMs of Myxobolus pseudodispar Gorbunova, 1936.

\begin{tabular}{lccc}
\hline Host (age group of fish) & No. of infected/exposed fish & Prevalence (\%) & Min.-Max. (Mean \pm SD*) spore No. \\
\hline roach Rutilus rutilus (Linnaeus) (1+) & $15 / 16$ & 94 & $1400-246667(49388 \pm 70054)$ \\
common bream Abramis brama (Linnaeus) (2+) & $4 / 16$ & 25 & $417-6250(599 \pm 1603)$ \\
rudd Scardinius erythrophthalmus (Linnaeus) (3+) & $0 / 16$ & 0 & 0 \\
\hline
\end{tabular}
* SD - standard deviation.
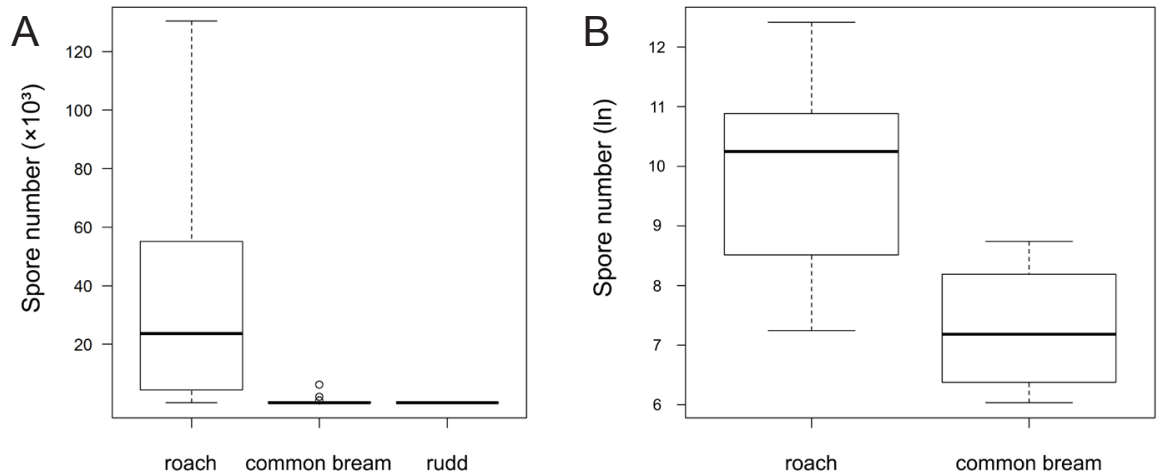

Fig. 1. The mean abundance (A) and the mean intensity (B) of experimental infection of roach, common bream and rudd with Myxobolus pseudodispar Gorbunova, 1936 Lineage GER triactinomyxons (TAMs) in experiment No. 1. The band inside the box is the median.

Fermentas), $2 \mathrm{mM} \mathrm{MgCl}, 0.2 \mathrm{mM}$ dNTP mix (Sigma), $0.5 \mu \mathrm{M}$ of each primer, and $1.25 \mathrm{u}$ of recombinant Taq DNA polymerase (Thermo Scientific, Fermentas). Amplification conditions were: initial denaturation at $95^{\circ} \mathrm{C}$ for $5 \mathrm{~min}$, then $95^{\circ} \mathrm{C}$ for $30 \mathrm{~s}, 59^{\circ} \mathrm{C}$ for $30 \mathrm{~s}$, and $72^{\circ} \mathrm{C}$ for $1 \mathrm{~min}$ for 35 cycles, with a terminal extension at $72{ }^{\circ} \mathrm{C}$ for 5 min. Purified PCR products were sequenced with the primers used for the amplification. Furthermore for M. pseudodispar samples, primers Myx4R or MB5 were applied for sequencing, for the accurate DNA sequence assembly (Table 2). For DNA sequencing, the ABI BigDye Terminator v3.1 Cycle Sequencing kit (Life Technologies, Carlsbad, CA, USA) with an ABI3100 Genetic Analyser was used.

\section{Phylogenetic analyses}

For the phylogenetic analyses, SSU rDNA partial sequences of 26 isolates of M. pseudodispar were used, of which 16 DNA sequences (NCBI Accession Number KU340976 to KU340991) were new additions in Genbank. For assembly, STADEN Sequence Analysis Package v1.7.0 (Bonfield et al. 1995) was applied. DNA sequences were manually edited and aligned using BioEdit Sequence Alignment Editor v7.2.5 (Hall 1999). After model test, maximum likelihood (ML) analysis was conducted using RAxML v8.2.4 (Stamatakis 2014) (model: GTR+I+G, bootstrap runs: 1000). Bayesian inference (BI) analysis was performed using MrBayes v3.2.6 (Huelsenbeck and Ronquist 2001) (number of runs: 2, number of generations: 1000000 , sample frequency: 100 , burn-in: $25 \%$ ).

\section{RESULTS}

\section{Fish exposure trials}

The infection prevalence was the highest in roach in both exposure trials (94\% and 80\%, respectively). While $25 \%$ of the exposed common bream were infected, no myxospores were detected in any of rudd specimens nei- ther in experiment No. 1 nor in experiment No. 2 (Tables 3 , 4, Figs. 1, 2). The standard deviations of spore numbers were high in every group, especially in roach where significantly higher number of myxospores was detected than in the infected common bream specimens (Tables 3, 4). The mean infection intensity was significantly different among fish groups $(p=0.0214)$, similarly to the mean abundance (Fig. 1). In experiment No. 2, the infection prevalence and intensity was somewhat lower in roach than in experiment No. 1 (Table 4, Fig. 2).

\section{Oligochaete exposure and identification}

Of all worm exposure trials, only isolates of M. pseudodispar from naturally infected roach and white bream developed TAMs in the exposed oligochaete stocks. Both natural isolates from roach and the lab-maintained Lineage GER isolate were successfully transmitted from fish to worm (F-W) in every case (Table 1). For the natural isolates from white bream, the F-W transmission was successful only once with remarkably lower infection intensity than for the isolates from roach (data not shown). Myxospores collected from naturally infected rudd and common bream did not result in TAM development in any of the infection trials (Table 1). In the molecular identification of randomly selected worm specimens, Limnodrilus hoffmeisteri Claparède and Tubifex tubifex (Müller) lineage II were identified as the major species components of the oligochaete stocks, similarly to the previous findings by Marton and Eszterbauer (2012).

\section{Phylogenetic analyses}

ML and BI analyses resulted in the same tree topology, although with slightly different bootstrap values/posterior probabilities. The phylogenetic positions of the isolates of $M$. pseudodispar examined in the present study and the 
Table 4. The infection prevalence and mean intensity in experiment No. 2. Two fish species were exposed with the Lineage GER TAMs of Myxobolus pseudodispar Gorbunova, 1936.

\begin{tabular}{lccc}
\hline Host (age group of fish) & No. of infected/exposed fish & Prevalence (\%) & Min.-max. (mean \pm SD) spore No. \\
\hline roach Rutilus rutilus (Linnaeus) (1+) & $16 / 20$ & 80 & $167-216500(15842 \pm 47656)$ \\
rudd Scardinius erythrophthalmus (Linnaeus) (1+) & $0 / 20$ & 0 & 0 \\
\hline SD - standard deviation. & &
\end{tabular}

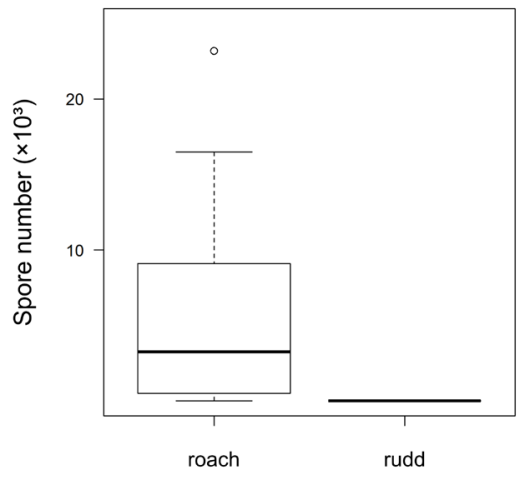

Fig. 2. The mean abundance of experimental infection of roach and rudd with Myxobolus pseudodispar Gorbunova, 1936 Lineage GER TAMs in experiment No. 2. The band inside the box is the median.

ones from the NCBI database have shown correlation to their host preference with some exceptions (Fig. 3). Including the sequences of $M$. pseudodispar deposited in GenBank by Molnár et al (2002), five major phylogenetic groups (clades Abramis, Blicca, Rutilus, Scardinius and Alburnus) were recognised, all of which differ in fish host species (Fig. 3). The isolates from bleak (Mp A-102B and Mp A-103B) had the most basal position in both analyses. The exceptions of host-clustering were five isolates, which grouped with ones from other host species (Mp BL1 from white bream grouped with isolates from common bream), or formed separate lineages outside of the main clades (Mp R-T42 and Mp R-T50 from roach, Mp AB1 from common bream and Mp SE-F69 from rudd) (Fig. 3). Within the five main phylogenetic groups, the genetic similarity was over 99\% (99.3-99.9\%), whereas interclade similarities were between 95.0 and $98.8 \%$ (Table 5).

\section{DISCUSSION}

The performed fish exposure trials confirmed the former theory by Molnár et al (2002) that roach is the most susceptible fish host for Myxobolus pseudodispar. In our study, both the prevalence and the intensity of infection in fish were the highest in roach compared to other examined cyprinids. Cech et al. (2012) referred to an unpublished study by Cs. Székely, who exposed oligochaetes with myxospores of $M$. pseudodispar from rudd, common bream, white bream and roach, but subsequent worm to fish transmissions were successful in roach only. Rudd, common bream, white bream, common carp, barbel, bleak, ide - Leuciscus idus (Linnaeus), vimba bream - Vimba vimba (Linnaeus) and nase - Chondrostoma nasus (Linnaeus) failed to get infected with $M$. pseudodispar. His

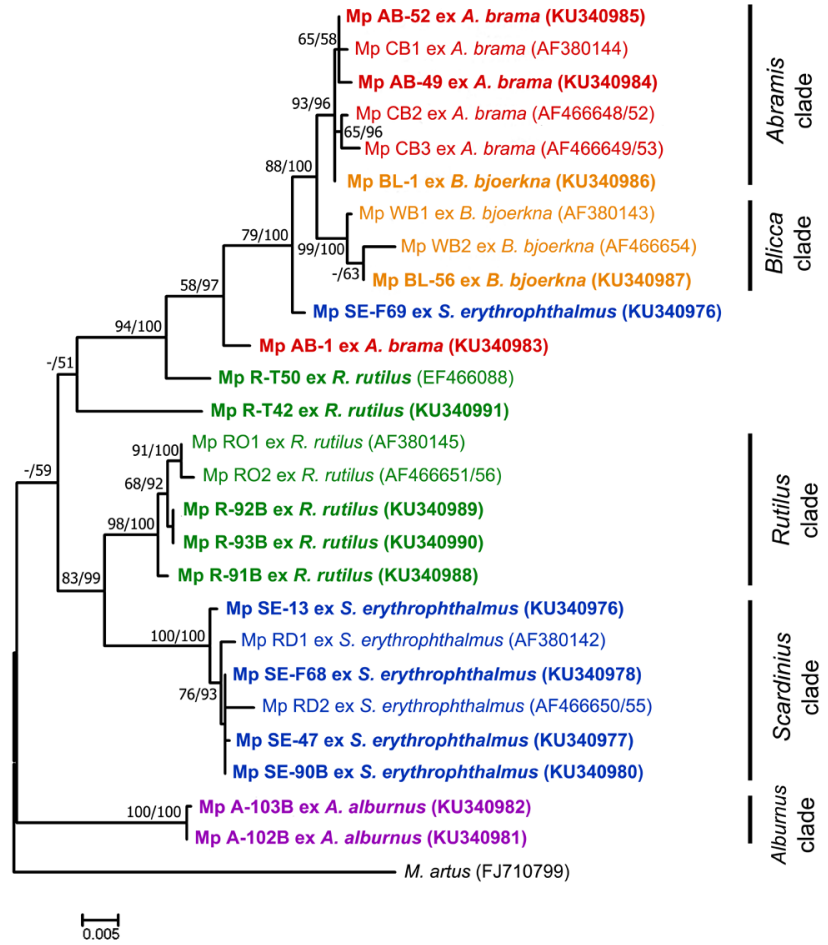

Fig. 3. Phylogenetic tree constructed by maximum likelihood and Bayesian inference analysis based on a 1852 bp long alignment of the SSU rDNA sequences of isolates of Myxobolus pseudodispar Gorbunova, 1936 from different host species. Maximum likelihood bootstraps and Bayesian posterior probabilities are given at nodes (in percent, \%). The number of changes per site is given by scale bar. Myxobolus artus was used as outgroup (black). Isolates are coloured for fish host: red - Abramis brama Linnaeus; yellow - Blicca bjoerkna Linnaeus; green - Rutilus rutilus Linnaeus; blue - Scardinius erythrophthalmus Linnaeus; purple-Alburnus alburnus Linnaeus. Newly sequenced taxa are in bold. Mp R-T50 is a triactinomyxon (TAM) isolate obtained from laboratory-maintained life cycle. GenBank accession numbers are in parentheses.

experimental findings, however, were not confirmed by genetic analysis and information on infection prevalence and intensity was not provided. Our experimental findings confirmed by molecular analysis showed that Lineage GER of M. pseudodispar from roach is able to infect other cyprinids like A. brama, although with lower prevalence and intensity. As rudd could not be infected in any examined age-groups, the host range of the parasite is limited as expected and it probably varies by parasite isolates. The age of rudd had most likely no effect on the 'resistance' as two age groups have been exposed ( $1+$ and $2+$ fish stocks). Moreover, the broodfish were obtained from different origin (lake Balaton and a fish hatchery), thus the possibility 
Table 5. Genetic similarity (\%) among isolates of Myxobolus pseudodispar (Mp) per phylogenetic clades in Fig. 3, based on 1264 bp long SSU rDNA alignment. Similarities within the main phylogenetic groups are highlighted in bold.

\begin{tabular}{lccccccccc}
\hline & MpSE & MpSE-F69 & MpA & MpAB & MpAB1 & MpBL & MpR & MpR-T42 & MpR-T50 \\
\hline Mp SE & $\mathbf{9 9 . 3 - 9 9 . 9}$ & & & & & & & & \\
Mp SE-F69 & $95.8-96.2$ & - & & & & & & & \\
Mp A & $95.4-95.9$ & 96.2 & $\mathbf{9 9 . 7}$ & & & & & & \\
Mp AB & $95.2-95.8$ & 98.9 & $95.0-95.4$ & $\mathbf{9 9 . 3 - 9 9 . 8}$ & & & & & \\
Mp AB1 & $95.5-95.9$ & 98.1 & 95.4 & $98.0-98.2$ & - & & & & \\
Mp BL & $95.0-95.5$ & $98.4-98.8$ & $95.1-95.4$ & $98.4-98.8$ & $97.2-97.4$ & $\mathbf{9 9 . 7}$ & & & \\
Mp R & $97.1-97.3$ & $95.6-96.1$ & $96.0-96.1$ & $95.6-95.9$ & $95.6-95.8$ & $95.4-95.8$ & $\mathbf{9 9 . 6 - 9 9 . 8}$ & & \\
Mp R-T42 & $96.0-96.2$ & 96.3 & $95.7-95.8$ & $95.6-95.8$ & 95.7 & $95.6-95.8$ & $96.5-96.8$ & - & \\
Mp R-T50 & $95.5-95.9$ & 97.2 & 96.2 & $96.4-96.6$ & 98.0 & $96.4-96.6$ & $96.3-96.5$ & 96.3 & - \\
\hline
\end{tabular}

SE - Scardinius erythrophthalmus; A - Alburnus alburnus; AB - Abramis brama; BL - Blicca bjoerkna; $\mathrm{R}$ - Rutilus rutilus .

of having the genetically similar, resistant fish stain at hand could also be excluded.

SSU rDNA-based phylogenetic analyses performed with ten isolates of $M$. pseudodispar originated from naturally infected fish showed that the isolates tend to cluster according to their fish host species (Molnár et al. 2002). This tendency is noticeable also in the present study, but some isolates from one cyprinid host cluster with those of another. Lineage GER of M. pseudodispar (= Mp R-T50 from roach) used for the fish exposure trials clustered as a basal lineage of the group composed of the isolates from $B$. bjoerkna and A. brama. Its phylogenetic position might explain why this isolate was able to infect common bream even though it is originally a roach parasite. It would have been interesting to investigate whether white bream was also susceptible to Lineage GER, but parasite-free white bream stock was not available for an exposure trial.

Oligochaete exposures (i.e. F-W transmission) aimed to prove whether TAMs were able to develop from different myxospore sources, either from natural infections of different fish species or from laboratory maintained life cycle of Lineage GER. Even though the worm stocks were mainly composed of the susceptible species T. tubifex lineage II and L. hoffmeisteri, the worms released TAMs when infected with myxospores from roach, or in one case, from white bream. Marton and Eszterbauer (2012) found that T. tubifex lineage II is susceptible to $M$. pseudodispar, but they could not detect released spores from $L$. hoffmeisteri in most of the cases. Although the composition of the worm stocks could have affected the outcome of the F-W transmission, it is more likely that the infectivity/virulence of the obtained TAMs (which looked mature morphologically) has more influence on the success of infection, and a certain malfunction in the infectivity caused the lower or zero prevalence for parasites originated from other cyprinid fish than roach.

Most of the isolates of M. pseudodispar were from natural infections obtained in Lake Balaton, Hungary. Lake Balaton, the largest natural freshwater lake in Central Europe, has special epizootiological importance due to its hydrological conditions and diverse fish fauna. All cyprinids which are common hosts of $M$. pseudodispar are native in the lake, just as the oligochaete fauna susceptible for the most common myxozoans in Hungary (El-Mansy et al. 1998, E.E. - unpubl. data). In oligochaetes from such a parasite-rich habitat, co-infection by several myxozoan species may take place in worm specimens (El-Mansy et al. 1998). El-Mansy et al. (1998) found that oligochaete individuals collected from Lake Balaton released various actinospore types (raabeia, TAM, aurantiactinomyxon) simultaneously for several months. As oligochaetes are the definitive hosts of many freshwater myxosporeans, thereby the sexual reproduction occurs in the worm (Morris 2012, Feist et al. 2015). It is theoretically possible that lineages of $M$. pseudodispar (i.e. genetically distinct clones) recombine in the worm in the course of reproduction, which could also increase the genetic diversity among isolates of M. pseudodispar.

Muscle-dwelling myxozoans were always somehow unique in this extent as the highest intraspecific diversity was detected only among the myxozoan species specialised on musculature (Molnár et al. 2002, 2012, Eszterbauer 2013, Molnár and Eszterbauer 2015). Besides M. pseudodispar, Myxobolus musculi is also frequently found in the skeletal muscle of certain cyprinids. Molnár et al. (2012) detected rather low, 97.0 to $97.6 \%$ genetic similarities among isolates of $M$. musculi from common barbel Barbus barbus (Linnaeus) and Iberian barbel Luciobarbus bocagei (Steindachner). If we consider the relatively high prevalence of $M$. pseudodispar infection in cyprinids (over $80 \%$ in roach in lake Balaton; K. Molnár, Institute for Veterinary Medical Research, Budapest, Hungary - pers. comm.), thereby the high probability of mating in the definitive host, this is the species which may have the chance for a quicker speciation compared to other, low abundant parasite species with similarly rare host species.

Parasites have different evolutionary strategies adapting to the changing environments, such as host-switch and host-shift (Rózsa et al. 2015). Host-shift is a gradual change of a wild host range when parasite species distinguish between primary and secondary hosts. The primary host is the one to which the parasite is well adapted, and it is the one that supports the survival of the parasite. The parasites are less adaptive to the secondary host and their reproductive success is less dependent on them. Between primary and secondary hosts, the parasite can carry out cross-infections and a prior primary host can change to secondary host or even become unsusceptible.

Host-switch is an abrupt random invasion of a new previously unsusceptible host species. It may step over large 
taxonomic gaps and it may lead to parasite speciation (Rózsa et al. 2015). Host-shift may occur in M. pseudodispar as well. It is considered a multi-host parasite species, and previous and present findings suggest that its primary host is roach, which is also the type host. Based on our experimental findings, the secondary host of Lineage GER of $M$. pseudodispar is common bream which is susceptible but only with significantly lower prevalence and intensity than the primary host, roach. However, other isolates of M. pseudodispar might have different primary and secondary hosts, and altogether the host range could be rather wide involving several other freshwater cyprinid species in which M. pseudodispar has never been detected. This theory would explain why infection prevalence and intensity in common bream were much lower than in roach. Based on this idea, rudd is neither the primary nor the secondary host of Lineage GER of $M$. pseudodispar. Therefore, no mature myxospores were developed in rudd, even though isolates of $M$. pseudodispar from rudd and roach are genetically closely related. The host-shift may explain the unexpected or uncertain phylogenetic position of certain isolates which clustered with different host species and not with the ones they were isolated from. They might have already started to shift to a new host while genetically they still cluster with other isolates from their former primary host species.

Whipps and Kent (2006) came to similar conclusions when studying the phylogeography of cosmopolitan marine myxozoan Kudoa thyrsites (Gilchrist, 1924) from 13 fish host species originating from eight different locations worldwide. They found that this myxozoan undergone a possible cryptic speciation and regionally endemic populations appeared due to geographic isolation. The ques- tion is if the myxospores developed in the secondary host are infective indeed or spore maturity issues (when spores look mature morphologically, but they are not or are less infective than the myxospores from the type host) occur in the new host.

These evolutionary strategies may promote the increase of species richness among Myxozoa and their wide geographic distribution as well. Based on these experimental and phylogenetic results, it seems that $M$. pseudodispar is a cryptic species complex, what is not a unique phenomenon for myxozoans either. Using molecular biological tools, Chloromyxum fluviatile Thélohan, 1892 and Zschokkella nova Klokachaeva, 1914 were found to be cryptic species complexes, whose genetic lineages were separated by geographic isolation or by host species (Lom and Dyková 1993, Fiala 2006, Bartošová and Fiala 2011). Our experimental findings supply further information regarding host specificity and they suggest that lineages of M. pseudodispar are not always strictly host-specific, but certain isolates may have stenoxenic nature as they are able to infect more than one, closely related host species. Further studies are planned to clarify the nature of host-shift in this common myxozoan species with special regard to the infectivity of the developed myxospores in different fish species.

Acknowledgements. Thanks are due to E. Rigler for the help with the statistical analysis, S. Marton, C. Guti for their assistance in DNA sequencing and E. Zsombory for the critical revision of the manuscript. We thank the anonymous reviewers for the careful reading of our manuscript, and their many insightful comments and suggestions. This study was supported by the Hungarian Scientific Research Fund (OTKA K112301).

\section{REFERENCES}

Barta J.R., Martin D.S., Liberator P.A., Dashkevicz M., Anderson J.W., Feighner S.D., Elbrecht A., Perkins-Barrow A., Jenkins M.C., Danforth H.D., Ruff M.D., Profous-Juchelka H. 1997: Phylogenetic relationships among eight Eimeria species infecting domestic fowl inferred using complete small subunit ribosomal DNA sequences. J. Parasitol. 83: 262-271.

Bartošová P., Fiala I. 2011: Molecular evidence for the existence of cryptic species assemblages of several myxosporeans (Myxozoa). Parasitol. Res. 108: 573-583.

BASKA F. 1987: Histological studies on the development of Myxobolus pseudodispar Gorbunova, 1936 in the roach (Rutilus rutilus). Acta Vet. Hung. 35: 251-257.

Beauchamp K.A., Kathman R.D., McDowell T.S., Hedrick R.P. 2001: Molecular phylogeny of tubificid oligochaetes with special emphasis on Tubifex tubifex (Tubificidae). Mol. Phylogenet. Evol. 19: 216-224.

Bonfield J.K., Smith K.F., Staden R. 1995: A new DNA sequence assembly program. Nucl. Acids Res. 23: 4992-4999.

Cech G., Molnár K., Székely C. 2012: Molecular genetic studies on morphologically indistinguishable Myxobolus spp. infecting cyprinid fishes, with the description of three new species, $M$. alvarezae sp. nov., M. sitjae sp. nov. and M. eirasianus sp. nov. Acta Parasitol. 57: 354-366.

Eiras J.C., Molnár K., Lu Y.S. 2005: Synopsis of the species of Myxobolus Bütschli, 1882 (Myxozoa: Myxosporea: Myxobolidae). Syst. Parasitol. 61: 1-46.
Eiras J.C., Zhang J., Molnár K. 2014: Synopsis of the species of Myxobolus Bütschli, 1882 (Myxozoa: Myxosporea, Myxobolidae) described between 2005 and 2013. Syst. Parasitol. 88: $11-36$.

El-Mansy A. Székely Cs. MolnáR K. 1998: Studies on the occurrence of actinosporean stages of myxosporeans in Lake Balaton, Hungary, with the description of triactinomyxon, raabeia and aurantiactinomyxon types. Acta Vet. Hung. 46: 437-450.

Eszterbauer E. 2004: Genetic relationship among gill-infecting Myxobolus species (Myxosporea) of cyprinids: molecular evidence of importance of tissue-specificity. Dis. Aquat. Org. 58: $35-40$.

ESZTERBAUER E. 2013: Intraspecific variability of freshwater $M y x$ obolus (Myxozoa) species on the basis of SSU rDNA: does tissue preference affect parasite speciation? 16th European Association of Fish Pathologists Int. Conf. Dis. Fish Shellfish, 2-6th September 2013, Tampere, Finland, Abstr. No O-061.

Eszterbauer E., Atkinson S., Diamant A., Morris D., El-Matbouli M., Hartikainen H. 2015b: Myxozoan Life Cycles: Practical Approaches and Insights. In: B. Okamura, A. Gruhl and J.L. Bartholomew (Eds.), Myxozoan Evolution, Ecology and Development. Springer International Publishing, Cham, pp. $175-198$.

Eszterbauer E., Forro B., Tolnai Z., Guti C.F., Zsigmond G., Hoitsy G., Kallert D.M. 2015a: Parental genetic diversity of brown trout (Salmo trutta m. fario) brood stock affects offspring susceptibility to whirling disease. Parasites \& Vectors 8: 141 . 
Eszterbauer E., Kallert D.M., Grabner D., El-Matbouli M. 2009: Differentially expressed parasite genes involved in host recognition and invasion of the triactinomyxon stage of Myxobolus cerebralis (Myxozoa). Parasitology 136: 367-377.

Eszterbauer E., Székely C. 2004: Molecular phylogeny of the kidney-parasitic Sphaerospora renicola from common carp (Cyprinus carpio) and Sphaerospora sp. from goldfish (Carassius auratus auratus). Acta Vet. Hung. 52: 469-478.

Eszterbauer E., Sipos D., Forró B., Bartosová P., Holzer A.S. 2013: Molecular characterization of Sphaerospora molnari (Myxozoa), the agent of gill sphaerosporosis in common carp Cyprinus carpio carpio. Dis. Aquat. Organ. 104: 59-67.

Faria J.C., Grosjean P., Jelihovschi E. 2013: Tinn-R-GUi/ Editor for R Language and Environment Statistical Computing, http://sourceforge.net/projects/tinn-R.

Feist S.W., Morris D.J., Alama-Bermejo G., Holzer A.S. 2015: Cellular Processes in Myxozoans. In: B. Okamura, A Gruhl and J.L. Bartholomew (Eds.), Myxozoan Evolution, Ecology and Development. Springer International Publishing, Cham, pp. 139-154.

Fiala I. 2006: The phylogeny of Myxosporea (Myxozoa) based on small subunit ribosomal RNA gene analysis. Int. J. Parasitol. 36 : $1521-1534$.

Fiala I., Bartošová-Sojková P., Whipps C.M. 2015: Classification and Phylogenetics of Myxozoa.In: B. Okamura, A. Gruhl and J.L. Bartholomew (Eds.), Myxozoan Evolution, Ecology and Development. Springer International Publishing, Cham, pp. $85-110$.

Hallett S.L., Diamant A. 2001: Ultrastructure and small-subunit ribosomal DNA sequence of Henneguya lesteri n. sp. (Myxosporea), a parasite of sand whiting Sillago analis (Sillaginidae) from the coast of Queensland, Australia. Dis. Aquat. Org. 46: 197-212.

Hall T.A. 1999: BioEdit: a user-friendly biological sequence alignment editor and analysis program for Windows 95/98/NT. Nucl. Acids Symp. Ser. 41: 95-98.

Huelsenbeck J.P., Ronquist F. 2001: MRBAYES: Bayesian inference of phylogenetic trees. Bioinformatics 17: 754-755.

Kallert D.M., El-Matbouli M. 2008: Differences in viability and reactivity of actinospores of three myxozoan species upon ageing. Folia Parasitol. 55: 105-110.

Kallert D.M., Eszterbauer E., Erséus C., El-Matbouli M., HaAs W. 2005: Life cycle studies of Myxobolus parviformis sp. n. (Myxozoa: Myxobolidae) from bream. Dis. Aquat. Org. 66 : 233-243.

Kallert D.M., Ponader S., Eszterbauer E., El-Matboul M., HaAs W. 2007: Myxozoan transmission via actinospores: new insights into mechanisms and adaptations for host invasion. Parasitology 134: 1741-1750.

LiU Y., Whipps C.M., Nie P., Gu Z. 2014: Myxobolus oralis sp. n. (Myxosporea: Bivalvulida) infecting the palate in the mouth of gibel carp Carassius auratus gibelio (Cypriniformes: Cyprinidae). Folia Parasitol. 61: 505-511.

Lom J., Dyкové I. 1992: Protozoan Parasites of Fishes, Vol. 26. Elsevier Science, Amsterdam, New York, 316 pp.
Loм J., Dyкové I. 1993: Scanning electron microscopic revision of common species of the genus Chloromyxum (Myxozoa: Myxosporea) infecting European freshwater fishes. Folia Parasitol. 40: $161-174$.

Lом J., DyкоvÁ I. 2006: Myxozoan genera: definition and notes on taxonomy, life-cycle terminology and pathogenic species. Folia Parasitol. 53: 1-36.

Marton S., Eszterbauer E. 2011: The development of Myxobolus pavlovskii (Myxozoa: Myxobolidae) includes an echinactinomyxon-type actinospore. Folia Parasitol. 58: 157-163.

Marton S., Eszterbauer E. 2012: The susceptibility of diverse species of cultured oligochaetes to the fish parasite Myxobolus pseudodispar Gorbunova (Myxozoa). J. Fish Dis. 35: 303-314.

MolnáR K. 1994: Comments on the host, organ and tissue specificity of fish myxosporeans and on the types of their intrapiscine development. Parasitol. Hung. 27: 5-20.

Molnár K., Eszterbauer E. 2015: Specificity of Infection Sites in Vertebrate Hosts. In: B. Okamura, A. Gruhl, J.L. Bartholomew (Eds.), Myxozoan Evolution, Ecology and Development. Springer International Publishing, Cham, pp. 295-313.

Molnár K., Eszterbauer E., Marton Sz., Székely Cs., EiRAS J.C. 2012: Comparison of the Myxobolus fauna of common barbel from Hungary and Iberian barbel from Portugal. Dis. Aquat. Org. 100: 231-248.

Molnár K., Eszterbauer E., Székely C., Dán Á., Harrach B. 2002: Morphological and molecular biological studies on intramuscular Myxobolus spp. of cyprinid fish. J. Fish Dis. 25: $643-652$.

MorRis D.J. 2012: A new model for myxosporean (Myxozoa) development explains the endogenous budding phenomenon, the nature of cell within cell life stages and evolution of parasitism from a cnidarian ancestor. Int. J. Parasitol. 42: 829-840.

Naldoni J., Zatti S.A., Capodifoglio K.R.H., Milanin T., Maia A.A.M., Silva M.R., Adriano E.A. 2015: Host-parasite and phylogenetic relationships of Myxobolus filamentum $\mathrm{sp}$. n. (Myxozoa: Myxosporea), a parasite of Brycon orthotaenia (Characiformes: Bryconidae) in Brazil. Folia Parasitol. 62: 014.

R Core Team 2003: A language and environment for statistical computing. R Foundation for Statistical Computing, Vienna, Austria.

Rózsa L., Tryjanowski P., Vas Z. 2015: Under the changing climate: how shifting geographic distributions and sexual selection shape parasite diversification. In: S. Morand, B.R. Krasnov and D.T.J. Littlewood (Eds.), Parasite Diversity and Diversification: Evolutionary Ecology Meets Phylogenetics. Cambridge University Press, Cambridge, pp. 58-71.

Stamatakis A. 2014: RAxML Version 8: A tool for Phylogenetic Analysis and Post-Analysis of Large Phylogenies. Bioinformatics 30: 13121-3.

Székely C., MolnáR K., Cech G. 2015: Description of Myxobolus balatonicus $\mathrm{n}$. sp. (Myxozoa: Myxobolidae) from the common carp Cyprinus carpio L. in Lake Balaton. Syst. Parasitol. 91: 71-79.

Whipps C.M., Kent M. 2006: Phylogeography of the cosmopolitan marine parasite Kudoa thyrsites (Myxozoa: Myxosporea). J. Eukaryot. Microbiol. 53: 364-373. 